\title{
Reliability, Validity and Usefulness of 30-15 Intermittent Fitness Test in Female Soccer Players
}

\author{
Nedim Čović ${ }^{1}$, Eldin Jelešković ${ }^{1}$, Haris Alić ${ }^{1}$, Izet Rađo ${ }^{1}$, Erduan Kafedžić ${ }^{2}$, \\ Goran Sporiš ${ }^{3}$, Daniel T. McMaster ${ }^{4,5}$ and Zoran Milanović ${ }^{6 *}$ \\ ${ }^{1}$ Faculty of Sport and Physical Education, University of Sarajevo, Sarajevo, Bosnia and Herzegovina, ${ }^{2}$ Institute of Kinesiology, \\ Sarajevo, Bosnia and Herzegovina, ${ }^{3}$ Faculty of Kinesiology, University of Zagreb, Zagreb, Croatia, ${ }^{4}$ Sport Performance \\ Research Institute New Zealand, AUT University, Auckland, New Zealand, ${ }^{5}$ Health, Sport and Human Performance, \\ University of Waikato, Hamilton, New Zealand, ${ }^{6}$ Faculty of Sport and Physical Education, University of Niš, Niš, Serbia
}

OPEN ACCESS

Edited by:

Francis Degache

University of Applied Sciences Western Switzerland, Switzerland

Reviewed by:

Pantelis Theodoros Nikolaidis, Hellenic Army Academy, Greece Davide Viggiano,

University of Molise, Italy

*Correspondence:

Zoran Milanovic zoooro_85@yahoo.com

Specialty section:

This article was submitted to

Exercise Physiology,

a section of the journal

Frontiers in Physiology

Received: 25 June 2016 Accepted: 17 October 2016 Published: 17 November 2016

Citation:

Čović N, Jelešković E, Alić H, Rađo I, Kafedžić E, Sporiš G, McMaster DT and Milanović Z (2016) Reliability, Validity and Usefulness of 30-15 Intermittent Fitness Test in Female

Soccer Players. Front. Physiol. 7:510

doi: 10.3389/fphys.2016.00510
PURPOSE: The aim of this study was to examine the reliability, validity and usefulness of the $30-15_{\text {IFT }}$ in competitive female soccer players.

METHODS: Seventeen elite female soccer players participated in the study. A within subject test-retest study design was utilized to assess the reliability of the 30-15 intermittent fitness test (IFT). Seven days prior to $30-15_{\mathrm{IFT}}$, subjects performed a continuous aerobic running test (CT) under laboratory conditions to assess the criterion validity of the $30-15_{\mathrm{IFT}}$. End running velocity $\left(\mathrm{V}_{\mathrm{CT}}\right.$ and $\left.\mathrm{V}_{\mathrm{IFT}}\right)$, peak heart rate (HRpeak) and maximal oxygen consumption $\left(\mathrm{VO}_{2 \max }\right)$ were collected and/or estimated for both tests.

RESULTS: $V_{\mathrm{IFT}}(\mathrm{ICC}=0.91 ; \mathrm{CV}=1.8 \%)$, HRpeak $(\mathrm{ICC}=0.94 ; \mathrm{CV}=1.2 \%)$, and $\mathrm{VO}_{2 \max }(\mathrm{ICC}=0.94 ; \mathrm{CV}=1.6 \%)$ obtained from the $30-15_{\mathrm{IFT}}$ were all deemed highly reliable $(p>0.05)$. Pearson product moment correlations between the CT and $30-15_{\text {IFT }}$ for $\mathrm{VO}_{2 \max }, \mathrm{HRpeak}$ and end running velocity were large $(r=0.67, p=0.013)$, very large $(r=0.77, p=0.02)$ and large $(r=0.57, p=0.042)$, respectively.

CONCLUSION: Current findings suggest that the $30-15_{\mathrm{IFT}}$ is a valid and reliable intermittent aerobic fitness test of elite female soccer players. The findings have also provided practitioners with evidence to support the accurate detection of meaningful individual changes in $V_{\mathrm{IFT}}$ of $0.5 \mathrm{~km} / \mathrm{h}$ (1 stage) and HRpeak of $2 \mathrm{bpm}$. This information may assist coaches in monitoring "real" aerobic fitness changes to better inform training of female intermittent team sport athletes. Lastly, coaches could use the $30-15_{\text {IFT }}$ as a practical alternative to laboratory based assessments to assess and monitor intermittent aerobic fitness changes in their athletes.

Keywords: 30-15 intermittent fitness test, aerobic, cardiorespiratory fitness, intermittent activity, soccer, high intensity interval training

\section{INTRODUCTION}

Female soccer has increased in popularity and participation over the past 20 years; as a result the skill level and physical demands of completion have also increased. The main characteristics of female and male soccer are similar in that match activity, aerobic power, sprinting capacity and exercise performance vary between playing positions (Rhodes and Mosher, 1992; 
Krustrup et al., 2005; Nikolaidis, 2014b). In addition, the physical profiles of the female soccer players defers between levels of competition; where elite players are faster, more powerful and have a greater aerobic capacity in comparison to non-elite players (Nikolaidis, 2010; MK Tood and Chisnal, 2013). Krustrup et al. (2005) has shown that average heart rate (HR) during matches was $87 \%$ of HRmax, with HRpeak values reaching 97\% HRmax during high intensity running (HIR) efforts. Of interest, the duration of and ability to repeat HIR was highly correlated with aerobic capacity $\left(\mathrm{VO}_{2 \max }\right)$, specifically in last 15 min of each half (Krustrup et al., 2005). However, HRpeak was poorly correlated with HIR; these findings support the notion that training prescription in female soccer should be based on individual high intensity intermittent aerobic fitness and not HRmax.

An apparent misinterpreted physiological response to intermittent high intensity interval training (HIIT) has emerged, as a result of negligence and a lack of understanding the information obtained from valid intermittent aerobic fitness tests (Buchheit, 2010). There are a number of field based fitness tests that attempt to predict aerobic capacity with varying levels of accuracy, including: the Montreal Track Test (Uger and Boucher, 1980); Yo-Yo Intermittent Recovery Test Level 1 (IR1) (Castagna et al., 2006; Dupont et al., 2010); and the multi-stage fitness test (Léger et al., 1988). A limitation with most of these aerobic fitness test is that athletes with lower maximal running speeds are required to perform supramaximal ( $>120 \%$ of aerobic capacity) high intensity efforts with directional changes at the same pace as faster athletes; and in turn are utilizing a higher proportion of their anaerobic speed reserve (Thomas et al., 2015).

For the purpose of resolving training intensity prescription issues in intermittent team sports, the 30-15 Intermittent Fitness Test (30-15 IFT) was developed (Buchheit, 2008; Haydar et al., 2011). The 30-15 IFT estimates aerobic capacity $\left(\mathrm{VO}_{2 \max }\right)$, determines maximal heart rate (HRmax) and anaerobic and intermittent HIR capacity (Buchheit and Rabbani, 2014; Thomas et al., 2015). The primary outcome measure of the $30-15_{\text {IFT }}$ is running velocity $\left(\mathrm{V}_{\mathrm{IFT}}\right)$ for the last completed stage (Buchheit, 2010), a suitable alternative to $\mathrm{vVO}_{2 \max }$ and HRpeak (Rabbania and Buchheita, 2015). As demonstrated, running speed at maximal oxygen uptake $\left(\mathrm{vVO}_{2 \max }\right)$ in continuous straight-line cardiorespiratory fitness tests is much lower than $\mathrm{V}_{\text {IFT, implying }}$ that anaerobic metabolism engagement is much higher in the 30-15 IFT (Buchheit, 2010). Lactic acid was up to $40 \%$ greater

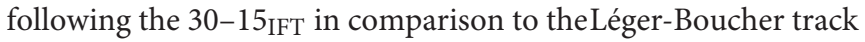
test (Buchheit et al., 2009a; Buchheit, 2010). In addition, $\mathrm{V}_{\text {IFT }}$ is highly correlated $(r=0.80)$ to other intermittent fitness tests (e.g., Léger-Boucher test and Yo-Yo IR1) end speed (Buchheit, 2008). The validity of $30-15_{\text {IFT }}$ simultaneously reflects broad spectrum of physiological, mechanical and neuromuscular components (Buchheit, 2008).

The 30-15 IFT was initially validated using female handball players (Buchheit, 2008, 2010). It has since been validated for elite ice hockey (Buchheit et al., 2011), male rugby (Scott et al., 2015), male semi-professional soccer (Thomas et al., 2015), and basketball (Buchheit, 2008, 2010) players. The reliability and effectiveness of $30-15_{\text {IFT }}$ to monitor intermittent fitness changes was also demonstrated in the above studies. The $30-15_{\text {IFT }}$ is highly reliable (ICC $=0.90-0.96$ ) across a range of sports, suggesting that a $\mathrm{V}_{\text {IFT }}$ change of $0.5 \mathrm{~km} / \mathrm{h}$ (1 running stage) is substantial (Buchheit, 2010) for detecting "real" changes in performance. The $30-15_{\text {IFT }}$ is also applicable to a number of other sports including: wheelchair basketball (Weissland et al., 2015), judo, futsal, netball and field hockey (Buchheit, 2010).

To date no research has investigated the reliability and validity of the $30-15_{\mathrm{IFT}}$, in comparison to a standard continuous incremental running test (CT) in elite female soccer players. Of interest is the practicality of the $30-15_{\text {IFT }}$ to provide coaches with a valuable aerobic fitness measure for the purpose of monitoring and determining the level of preparedness of elite female soccer players. The aim of this study was to examine the reliability, validity and usefulness of the $30-15_{\text {IFT }}$ in competitive female soccer players. It is expected that $30-15_{\text {IFT }}$ will be highly reliable and a valid indicator of aerobic fitness and HRmax; and in turn should provide meaningful intermittent fitness data $\left(\mathrm{V}_{\mathrm{IFT}}\right)$ for individualized high intensity interval training (HIIT) prescription.

\section{METHODS}

\section{Experimental Approach and Design}

A within subject test-retest study design was utilized; where the $30-15_{\text {IFT }}$ was performed on two separate occasions (7 days between trials). Seven days prior to $30-15_{\mathrm{IFT}}$, subjects performed a CT under laboratory conditions. The CT was used to precisely estimate $\mathrm{VO}_{2 \max }$ and HRmax. The CT was performed at the beginning of preparation period after 1 week of low intensity soccer training. The $30-15_{\text {IFT }}$ test-retest were performed at the same time of day (12.00-13.00). A standard indoor facility $(40 \times 20 \mathrm{~m})$ with synthetic non-slippery surface was used for

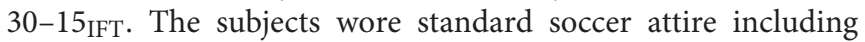
personal boots and were asked to refrain from performing any intense physical activity $48 \mathrm{~h}$ prior to testing.

\section{Subjects}

Seventeen well trained (training age $=5$ years) elite female soccer players (age $=22.8 \pm 4.3$ years; height $=164 \pm 6.9 \mathrm{~cm}$; body mass $=57.3 \pm 9.2 \mathrm{~kg}$ ) participated in the study. Participants were members of the state champion's soccer club; in addition eight of the subjects play for the senior national team. The subjects trained $5.4 \pm 1.7$ times per week $(9.9 \pm 2.3 \mathrm{~h}$ per week). All subjects were free of injury, illness and disease as determined by a medical examination prior to study participation. Seventeen players completed the initial 30-15 IFT and continuous running test (CT). One player was excluded from the remainder of the study due to a previous injury; and data from four of the subjects following CT were excluded due to methodological issues (one subject was removed due to the loss of transmission from the HR belt and three due to inappropriate data storage). Sixteen subjects were included for the test-retest reliability and 13 subjects for validation of the 30-15 IFT. The study was approved by the Ethics Committee of the Faculty of Sport and Physical Education, University of Sarajevo according to the Helsinki Declaration guidelines. Participants were fully informed and signed a consent 
form that indicated they could withdraw from the study at any time.

\section{Continuous Incremental Running Test}

Each player performed the Taylor running continuous exercise protocol (Taylor et al., 1955) under laboratory conditions $\left(\sim 22^{\circ} \mathrm{C}\right.$ room temperature). The graded $\mathrm{CT}$ featured running on motor driven treadmill (Cosmed, Rome, Italy) at slope angle of $1.5^{\circ}$. Participants performed the following lower limb dynamic stretches prior to the CT: leg swings, walking lunges, side lunges, ankle bounce, and single leg bounce. The initial stages of the CT served as the warm-up. Firstly, the subjects were monitored at speed of $3 \mathrm{~km} / \mathrm{h}$ for $3 \mathrm{~min}$. The velocity was than increased to $7 \mathrm{~km} / \mathrm{h}$ followed by automated speed increase of $1 \mathrm{~km} / \mathrm{h}$ each minute until volitional exhaustion (failure). An automated breath-by-breath respiratory system (K4b2, Cosmed, Rome, Italy) was used to analyze the gas exchange. All cardiorespiratory data $\left(\mathrm{VO}_{2}\right.$-oxygen uptake, $\mathrm{VCO}_{2}$-carbon dioxide output, VTtidal volume, VE-minute ventilation, RER-respiratory exchange ratio as well as $\mathrm{PO}_{2}$ and $\mathrm{PCO}_{2}$ tidal volume) were averaged across $5 \mathrm{~s}$ time intervals. Highest $\mathrm{VO}_{2}$ consumption obtained from four average values (20 s) was defined as the maximal oxygen uptake $\left(\mathrm{VO}_{2 \max }\right)$. Heart rate was also monitored in real time at frequency of $1 \mathrm{~Hz}$ (Polar Electro Oy, Finland). Heart rate at $\mathrm{VO}_{2}$ peak represented HRpeak. Running velocity reached at $\mathrm{VO}_{2 \text { peak }}$ presented tests end speed $\left(\mathrm{V}_{\mathrm{CT}}\right)$. For the purpose of ensuring maximum effort and volitional exhaustion was achieved the following criteria were implemented: HRpeak within $5 \%$ of the predicted HRmax (220-age), RER $>1.15, \mathrm{VE} / \mathrm{VO}_{2}<30$ and blood lactate $>8 \mathrm{mmol} / \mathrm{l}$. Gas analyzer was calibrated according to manufacturer recommendations (Duffield et al., 2004) prior to each test.

\section{The 30-15 Intermittent Fitness Test}

Athletes performed a set of five dynamic stretches (leg swings, walking lunges, side lunges, ankle bounce and single leg bounce) prior to the $30-15_{\text {IFT. The }} 30-15_{\text {IFT }}$ was performed as described previously (Buchheit, 2008). The test consists of $30 \mathrm{~s}$ shuttle runs interspersed with $15 \mathrm{~s}$ passive recovery periods. Subjects performed shuttles between two lines ( $40 \mathrm{~m}$ apart) at a given pace of pre-recorded audio beeps. The test starts at a velocity of $8 \mathrm{~km} / \mathrm{h}$ and increases by $0.5 \mathrm{~km} / \mathrm{h}$ for each successive $30 \mathrm{~s}$ stage. Players were verbally encouraged to complete as many stages as possible. The test ended, when the player (i) was totally exhausted and stopped on her own volition or (ii) if she was unable to reach the next 3-meter zone at the beep on three successive occasions. The running velocity during the last completed stage was taken as the maximum running speed $\left(\mathrm{V}_{\mathrm{IFT}}\right)$. Estimated $\mathrm{VO}_{2 \text { maxIFT }}$ was calculated from $V_{\text {IFT }}$ and the athlete's gender $(\mathrm{G})$, age $(A)$ and body mass (BM) as follows (Buchheit, 2008):

$$
\begin{aligned}
\mathrm{VO}_{2 \operatorname{maxIFT}}(\mathrm{ml} / \mathrm{min} / \mathrm{kg})= & 28.3-2.15 \mathrm{G}-0.741 \mathrm{~A}-0.0357 \mathrm{BM} \\
& +0.058 \mathrm{AXV}_{\mathrm{IFT}}+1.03 \mathrm{~V}_{\mathrm{IFT}} .
\end{aligned}
$$

A video (Sony DSLR-A700) recording of the test was reviewed for cases where $\mathrm{V}_{\text {IFT }}$ was uncertain. Heart rate was also monitored in real time at frequency of $1 \mathrm{~Hz}$ (Polar Electro Oy, Finland) during each test.

\section{Statistical Analysis}

Means and standard deviations (SD) with 90\% confidence interval limits $(90 \% \mathrm{CI})$ were used to represent centrality and spread of data. Data normality was assessed using Shapiro-Wilk test he inspection of Q-Q plots and the homogeneity of the variance was verified using Levene test. Paired sample $t$-tests were used to determine if a learning effect occurred between $30-15_{\text {IFT }}$ testing sessions. Standardized differences in mean were calculated to determine the magnitude of the change across and between tests. According to Hopkins et al. (2001) effect size (ES) magnitudes of change were classified as trivial $(>0.2)$, small (0.2-0.5), moderate (0.5-0.8); large (0.8-1.60), and very large $(>1.60)$. Reliability of the change in the mean between trials was determined using intraclass correlation coefficient (ICC), typical error (TE) expressed as coefficient of variation (CV\%) and smallest worthwhile change (SWC); an Excel spread sheet supplied by Hopkins (2007) was used for the calculations. ICC values of $0.1,0.3,0.5,0.7,0.9$, and 1.0 were classified as low, moderate, high, very high, nearly perfect, and perfect, respectively. The following criteria was used to declare good reliability: $\mathrm{CV}<5 \%$ and ICC $>0.69$ (Buchheit et al., 2011). Appropriate performance usefulness indicators in accordance to the noise of the test result and measurement uncertainty (Hopkins, 2004) was assessed via the magnitude of the SWC. A comparison of SWC (0.2 multiplied by the between-subject SD, based on Cohen's effect size) to TE was used to establish the usefulness of a given dependent variable as follows: "Marginal" (TE > SWC), "OK" (TE = SWC) and "Good" (TE < SWC). SWC was calculated for $\mathrm{V}_{\mathrm{IFT}}$, and HRpeak. Degree of coherence between $\mathrm{VO}_{2 \max }$, HRpeak and end speed of 30-15 IFT and CT was assessed using Pearson's product-moment correlation $(r)$. Additionally, the relationship between $\mathrm{VO}_{2 \max }$ obtained from $\mathrm{CT}$ and $\mathrm{V}_{\text {IFT }}$ from 30-15 $5_{\text {IFT }}$ was also investigated. Correlation values denoted association between variables and tests as small $(r=0.1-0.3)$, moderate $(r=0.3-0.5)$, large $(r=0.5-0.7)$, very large $(r=0.7-0.9)$, and almost perfect $(r=0.9-1.0)$. In a cases where small positive and negative values of confident intervals (90\% CI) overlapped magnitude, the value was declared as unclear, otherwise the magnitude was deemed as observed (Hopkins, 2004). In addition, analysis of variance $(2 \times 2$ ANOVA) was performed to determine $30-15_{\text {IFT }}$ performance differences between national squad (NS) and national club (NC) level players. Partial eta squared $\left(\eta^{2}\right)$ values of $0.02,0.13$, and 0.33 rated difference as small, moderate and high (Pierce et al., 2004). Statistical significance was indicated in cases where $p$-value was less than 0.05 .

\section{RESULTS}

\section{Reliability}

Similar $\mathrm{V}_{\text {IFT }}$ (test $=17.1 \pm 1.0 \mathrm{~km} / \mathrm{h}$; retest $=17.4 \pm 0.9$ km/h), HRpeak (test $=196 \pm 7$ b.p.m; retest $=197 \pm 5$ b.p.m.) and $\mathrm{VO}_{2 \max }$ (test $=45.8 \pm 2.8 \mathrm{ml} / \mathrm{kg} / \mathrm{min}$; retest $=46.5 \pm$ $2.7 \mathrm{ml} / \mathrm{kg} / \mathrm{min}$ ) values were observed between $30-15_{\text {IFT }}$ testing 
sessions. Non-significant differences $(p>0.05)$ were observed between testing sessions for HRpeak ( $\mathrm{ES}=$ trivial; CI 90\% $(-1.95$; $0.82), p=0.48), \mathrm{V}_{\text {IFT }}$ (ES = small; CI 90\% $(-0.48 ;-0.09), p=$ $0.23)$ and $\mathrm{VO}_{2 \max }$ [ES = small; CI 90\% $\left.(-1.31 ;-0.47), p=0.20\right]$ as observed in Table 1. High test-retest reliability (ICC > 0.90; $\mathrm{TE}<1.9 \%$ ) was observed for all measures.

\section{Test Usefulness}

The $\mathrm{TE}$ for $\mathrm{V}_{\text {IFT }}(\mathrm{TE}=0.31 \mathrm{~km} / \mathrm{h})$ and $\mathrm{VO}_{2 \max }(\mathrm{TE}=$ $0.71 \mathrm{ml} / \mathrm{kg} / \mathrm{min}$ ) was greater than the presumed SWC (SWC $=0.20 \mathrm{~km} / \mathrm{h}$ and $\mathrm{SWC}=0.55 \mathrm{ml} / \mathrm{kg} / \mathrm{min}$ ), consequently these measure were rated as "marginal." In contrast, TE for HRpeak ( 2 b.p.m) was similar to SWC and was rated as "OK."

\section{Validity of the Test}

Large to very large significant differences $(p<0.05)$ were observed between the CT and 30-15 IFT $_{\text {for }} \mathrm{VO}_{2 \max }[\mathrm{ES}=-1.10$; $p=0.001$; CI 90\% $(-4.5 ;-3.5)], \mathrm{V}_{\mathrm{CT} / \mathrm{IFT}}[\mathrm{ES}=-0.98 ; p<0.001$; CI 90\% (-7;-3)], and HRpeak (ES $=-1.60 ; p<0.001$; CI $90 \%(-12 ;-7)$; Table 2$)$. Large to very large correlations were observed between the CT and 30-15 IFT for $\mathrm{VO}_{2 \max }(r=0.67, p$ $=0.013$ ) and HRpeak $(r=0.77, p=0.02)$. Large to very large correlations were also observed between $\mathrm{V}_{\text {IFT }}$ and the following variables: $\mathrm{V}_{\mathrm{CT}}(r=0.57, p=0.042)$, CT-VO $\mathrm{V}_{2 \max }(r=0.67, p$ $=0.027$; Figure 1) and 30-15 $\mathrm{IFT}-\mathrm{VO}_{2 \max }(r=0.88, p<0.001$; Figure 2). Figure 1 explains linear relationship between maximal oxygen consumption measured directly using CT and 30-15 IFT end speed in 13 players and suggesting that significantly high relationship. In Figure 2, a consistent linear dependence for the maximal oxygen consumption measured indirectly from 30$15_{\text {IFT }}$ end speed using mathematical formula and $V_{\text {IFT }}$ for sample of 16 players was highlighted.

\section{Comparison between Performance Groups

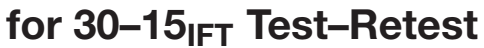

National squad players $\mathrm{V}_{\text {IFT }}$ (mean difference: $1.15 \mathrm{~km} / \mathrm{h}$; CI $90 \%$ (0.58; 1.73); $F=16.96, p<0.001 ; \eta^{2}=0.37$ ), HRpeak (mean difference: 4 b.p.m; CI 90\% $(0.5 ; 8.8) ; F=4.29, p=0.048 ; \eta^{2}=$ 0.13 ) and predicted $\mathrm{VO}_{2 \max }$ (mean difference: $2.2 \mathrm{ml} / \mathrm{kg} / \mathrm{min} ; \mathrm{CI}$

TABLE 1 | Reliability measure values for maximal reached speed ( $\left.\mathrm{V}_{\mathrm{IFT}}\right)$, peak heart rate (HRpeak) and maximal oxygen consumption $\left(\mathrm{VO}_{2 \max }\right)$ in 30-15 intermittent fitness test.

\begin{tabular}{|c|c|c|c|}
\hline & $\mathrm{V}_{\mathrm{IFT}}(\mathbf{k m} / \mathrm{h})$ & $\begin{array}{l}\text { HRpeak } \\
\text { (b.p.m.) }\end{array}$ & $\begin{array}{c}\mathrm{VO}_{2 \max } 30-15_{\mathrm{IFT}} \\
(\mathrm{ml} / \mathrm{kg} / \mathrm{min})\end{array}$ \\
\hline ES & -0.29 (Small) & -0.14 (Trivial) & -0.26 (Small) \\
\hline Diff $(90 \% \mathrm{Cl})$ & $0.28(-0.48 ;-0.09)$ & $<1(-1.95 ; 0.82)$ & $0.89(-1.31 ;-0.47)$ \\
\hline ICC $(90 \% \mathrm{Cl})$ & $0.91(0.80 ; 0.96)$ & $0.94(0.85 ; 0.97)$ & $0.94(0.87 ; 0.98)$ \\
\hline TE $(90 \% \mathrm{Cl})$ & $0.31(0.24 ; 0.45)$ & $2.0(1.73 ; 3.21)$ & $0.71(0.55 ; 1.02)$ \\
\hline CV\% (90\%Cl) & $1.8(1.4 ; 2.7)$ & $1.2(0.9 ; 1.7)$ & $1.6(1.2 ; 2.3)$ \\
\hline SWC\% & $0.20(1.2 \%)$ & $2.0(0.7 \%)$ & $0.55(1.2 \%)$ \\
\hline Rating & Marginal & OK & Marginal \\
\hline
\end{tabular}

ES, effect size; ICC, intraclass correlation coefficient; TE, typical error of measurement; $\mathrm{CV}$, Coefficient of variation; SWC, smallest worthwhile change; $\mathrm{Cl}$, confidence intervals. $\left.90 \%(0.36 ; 4.0), F=6.0, p=0.021 ; \eta^{2}=0.17\right)$ were significantly greater in comparison to national club level players (Table 3 ). Figure 3 presents a graphical interpretation of the differences between in $\mathrm{V}_{\text {IFT }}$, HRpeak and $\mathrm{VO}_{2 \max }$ expressed in standardized units (Z-scores) for the NS and NC level players.

\section{DISCUSSION}

The aim of this study was to assess the reliability, validity and usefulness of the 30-15 IFT for assessing intermittent aerobic fitness in elite female soccer players. The $V_{\text {IFT }}$ and HRpeak obtained from the 30-15 IFT were deemed reliable for estimating intermittent fitness capacity and HRpeak of elite female soccer players. The 30-15 IFT also provided a quality estimate of aerobic fitness $\left(\mathrm{VO}_{2 \max }\right)$; which is in agreement with previous studies (Buchheit, 2008, 2010; Thomas et al., 2015).

The $\mathrm{V}_{\mathrm{IFT}}$ reliability findings herein were $(\mathrm{TE}=0.31 \mathrm{~km} / \mathrm{h}$, $\mathrm{CV}=1.8 \%$; ICC $=0.91$ ) were similar to previous investigations; that observed low typical error $(\mathrm{CV}=0.8$ to $1.9 \%)$ in male and female team sport athletes (e.g., soccer, ice hockey, rugby and handball) (Buchheit, 2005; Buchheit et al., 2011; Scott et al., 2015; Thomas et al., 2015). A small learning effect for the 30$15_{\text {IFT }}$ was observed, as a "small" non-significant increase in $\mathrm{V}_{\text {IFT }}$ was observed from the first to the second testing session; this most likely occurred to the group's lack of experience in performing the test. Current reliability findings were also similar to other intermittent field tests, such as Yo-Yo IR1 (CV < 2.0\%) (Krustrup and Bangsbo, 2001; Thomas et al., 2006) and YoYo IR2 conducted on male and female team sport athletes (Thomas et al., 2006; Bangsbo et al., 2008). Based on previous research, Yo-Yo IR tests can also be used as an indicator of the intermittent aerobic fitness in elite female soccer players (Krustrup et al., 2005). In light of the fact that the Yo-Yo IR1 and 30-15 IFT assess different physical capacities, a large correlation $(r=0.75)$ was observed between the two intermittent fitness tests with similar levels of sensitivity following an 8 week training intervention in male soccer players (Buchheit and Rabbani, 2014). The high reliability of HRpeak (TE $=2$ b.p.m; $\mathrm{CV}=1.2 \%$; ICC $=0.94$ ) during the $30-15_{\text {IFT }}$ in elite female soccer players further supports the outcomes of previous research (Buchheit et al., 2011; Scott et al., 2015). The sample size used herein for 30-15 IFT test-retest reliability $(n=16)$ and validation $(n=13)$ were characterized as small; however the high reliability outcomes annulled the small sample size (Hopkins et al., 2001).

The criterion validity of the $30-15_{\text {IFT }}$ was assessed by comparing outcome measures to the CT (laboratory test), which is considered the "gold standard" for estimating $\mathrm{VO}_{2 \mathrm{max}}$. Due to relationship between HRpeak and $\mathrm{VO}_{2 \max }$ in field based tests (Scott et al., 2015) validation of $30-15_{\mathrm{IFT}}$ in comparison to a CT is justified for cardiorespiratory and cardiovascular performance. Large and very large linear relationships were observed between the 30-15 IFT and CT for $\mathrm{VO}_{2 \max }(r=0.67)$ and HRpeak $(r=0.77)$, which supports the validity of the 30${ }_{15}$ IFT for assessing maximal aerobic fitness in female soccer players. In addition, $\mathrm{V}_{\mathrm{IFT}}$ was highly correlated with $\mathrm{CT} \mathrm{VO}_{2 \max }$ 
TABLE 2 | Observed output for maximal oxygen consumption $\left(\mathrm{VO}_{2 \mathrm{max}}\right)$ and peak heart rate (HRpeak) during $30-15$ Intermittent Fitness Test (30-15 1 IFT) and Continuous running test (CT).

\begin{tabular}{|c|c|c|c|c|c|c|}
\hline & CT & $30-15_{\text {IFT }}$ & Diff. (90\% Cl) & ES & $r(90 \% \mathrm{Cl})$ & Rating \\
\hline $\mathrm{VO}_{2 \max }$ & $40.5 \pm 5.9$ & $45.8 \pm 2.9^{\star \star}$ & $5.3(-7 ;-3)$ & -1.10 & $0.67^{\star}(0.28 ; 0.87)$ & Large \\
\hline HRpeak & $185.7 \pm 5.2$ & $195.8 \pm 7.2^{\star \star}$ & $10.1(-12 ;-7)$ & -1.60 & $0.77^{\star \star}(0.46 ; 0.91)$ & Very large \\
\hline ERV & $13.2 \pm 1.2$ & $17.1 \pm 1.0^{\star \star}$ & $4.0(-4.5 ;-3.5)$ & -0.98 & $0.57^{\star}(0.13 ; 0.82)$ & Large \\
\hline
\end{tabular}

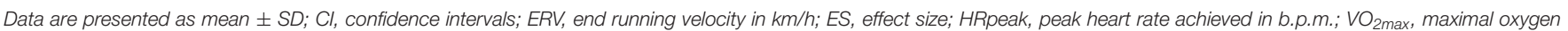
uptake in $\mathrm{ml} / \mathrm{kg} / \mathrm{min} ;{ }^{* *} \mathrm{p}<0.01,{ }^{*} \mathrm{p}<0.05$

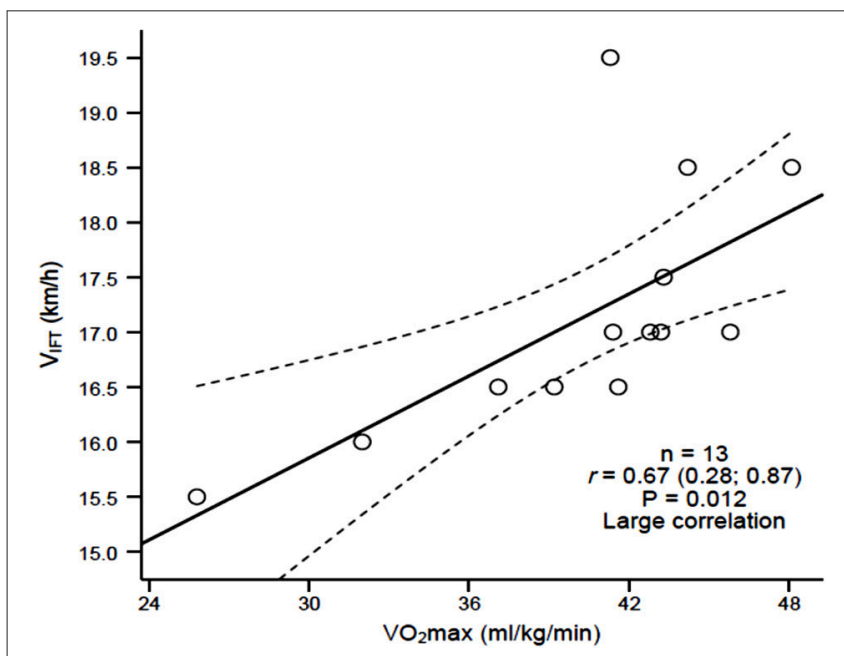

FIGURE 1 | Relationship between 30-15 IFT $_{\text {end speed }}\left(\mathrm{V}_{\mathrm{IFT}}\right)$ and measured maximal oxygen consumption $\left(\mathrm{VO}_{2 \max }\right)$ obtained from the incremental continuous running treadmill test.

$(r=0.67)$. Similar relationships between $\mathrm{VO}_{2 \max }$ and Yo-Yo IR1 performance $(r=0.70)$ (Bangsbo et al., 2008) in 141 athletes and Yo-Yo IR2 performance $(r=0.68)$ in elite female soccer players were observed (Bradley et al., 2014). Krustrup et al. (2005), observed a slightly weaker relationships $(r=0.55)$ between $\mathrm{VO}_{2 \max }$ and Yo-Yo IR1 in elite female soccer players. $\mathrm{VO}_{2 \max }$ estimated from $\mathrm{V}_{I F T}$ had a very large correlation $(r=0.88)$ to $\mathrm{CT}-\mathrm{VO}_{2 \max }$; therefore is deemed a valid and reliable alternative of predicting maximal aerobic fitness. As expected, the $\mathrm{VO}_{2 \max }$ and HRpeak values from the $30-15_{\text {IFT }}$ were significantly $(p<$ 0.01 ) larger $(\mathrm{ES}>0.8)$ than those values obtained from the CT. $\mathrm{V}_{\text {IFT }}$ obtained from the $30-15_{\text {IFT }}$ was $4 \mathrm{~km} / \mathrm{h}$ higher than $\mathrm{V}_{\mathrm{CT}}$ obtained during the CT, which is in agreement to previously predictive differences (2 to $5 \mathrm{~km} / \mathrm{h}$ ) (Buchheit, 2010). Current findings also support those of Buchheit (2010), implying that $\mathrm{V}_{\text {IFT }}$ is a valid measure of an athlete's physical fitness, and is more closely related to $\mathrm{VO}_{2 \max }$ and repeated intense running ability than it is to local muscular fatigue (Buchheit et al., 2011).

An intermittent fitness tests sensitivity to detect meaningful changes is vital to performance monitoring. The ability of the $30-$ $15_{\text {IFT }}$ to detect meaningful changes in performance, which was assessed by comparing the TE to the SWC. Outcomes revealed that the $\mathrm{V}_{\text {IFT }}$ was deemed "marginally" useful, as the TE $(0.31$ $\mathrm{km} / \mathrm{h})$ was slightly larger than SWC $(0.20 \mathrm{~km} / \mathrm{h})$; however, both

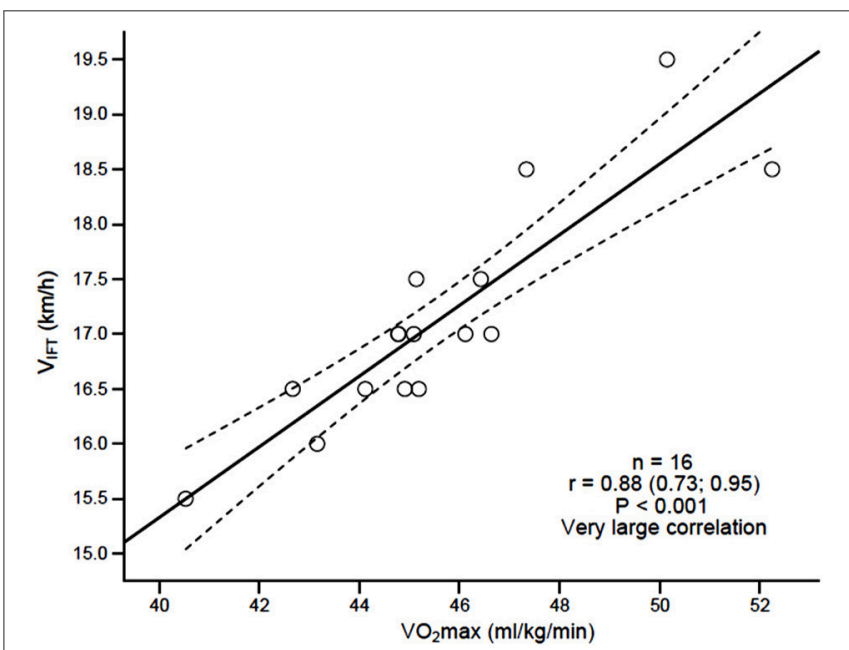

FIGURE 2 | Linear dependence of estimated maximal oxygen consumption $\left(\mathrm{VO}_{2}\right.$ max) based on $30-15_{\mathrm{IFT}}$ end speed $\left(\mathrm{V}_{\mathrm{IFT}}\right)$.

the TE and SWC were lower than $0.5 \mathrm{~km} / \mathrm{h}$ (one running stage), suggesting that an individual performance change as low as one stage $( \pm 0.5 \mathrm{~km} / \mathrm{h})$ to be "real and meaningful." This is an agreement to previous findings, whom found that a $30-15_{\text {IFT }}$ performance change of one stage $(0.5 \mathrm{~km} / \mathrm{h})$ is "meaningful" (Buchheit, 2010; Scott et al., 2015). Recommended VIFT threshold values of $6-8 \%$ have been established previously as the minimal difference needed to be considered a "real" performance change for a group of athletes (Buchheit et al., 2009b,c; Buchheit et al., 2011). Furthermore, HRpeak was also deemed useful for detecting "meaningful" individual changes as small as 2 b.p.m; which is in agreement to previous findings in male rugby league players (Scott et al., 2015).

A comparison of NS and NC level players revealed significant differences in 30-15 IFT test-retest performance. NS players reached significantly greater $\mathrm{V}_{\text {IFT }}$ and HRpeak in comparison to NC players (Table 3). A mean $\mathrm{V}_{\text {IFT }}$ difference of $1.15 \mathrm{~km} / \mathrm{h}$ was observed between groups, suggesting that there was a meaningful difference $\left(\mathrm{V}_{\text {IFT }}>0.5 \mathrm{~km} / \mathrm{k}\right)$ in $30-15_{\text {IFT }}$ performance between NS and NC level players. Other studies have also observed meaningful difference in 30-15 IFT performance (Buchheit, 2010; Scott et al., 2015). Mohr et al. (2008) and Andersson et al. (2010) between international world-class athletes and sub-elite national level athletes. These studies concluded that world-class international players performed a greater number of 
TABLE 3 | Rated differences of the $30-15_{\mathrm{IFT}}$ test-retest performance for test end speed ( $\mathrm{V}_{\mathrm{IFT}}$ ), heart rate peak (HRpeak) and indirect maximal oxygen consumption $\left(\mathrm{VO}_{2 \mathrm{max}}\right)$ between national selection level $(n=8)$ and national league level $(n=8)$ players.

\begin{tabular}{|c|c|c|c|c|c|c|}
\hline & \multicolumn{2}{|c|}{ NS } & \multicolumn{2}{|c|}{ NC } & $F(p)$-value & Ratins \\
\hline HRpeak (b.p.m.) & $199 \pm 4.0$ & $199 \pm 4.0$ & $194 \pm 8.0$ & $195 \pm 6.0$ & 4.29 (0.048) & High \\
\hline $\mathrm{V}_{\mathrm{IFT}}(\mathrm{km} / \mathrm{h})$ & $17.68 \pm 1.0$ & $18.00 \pm 1.0$ & $16.56 \pm 0.49$ & $16.81 \pm 0.26$ & $16.96(<0.001)$ & High \\
\hline
\end{tabular}

Data are presented as mean $\pm S D$; NS, national squad players; NC, national club league players; $V_{I F T}$, end running velocity; HRpeak, peak heart rate; VO 2 max, maximal oxygen uptake.

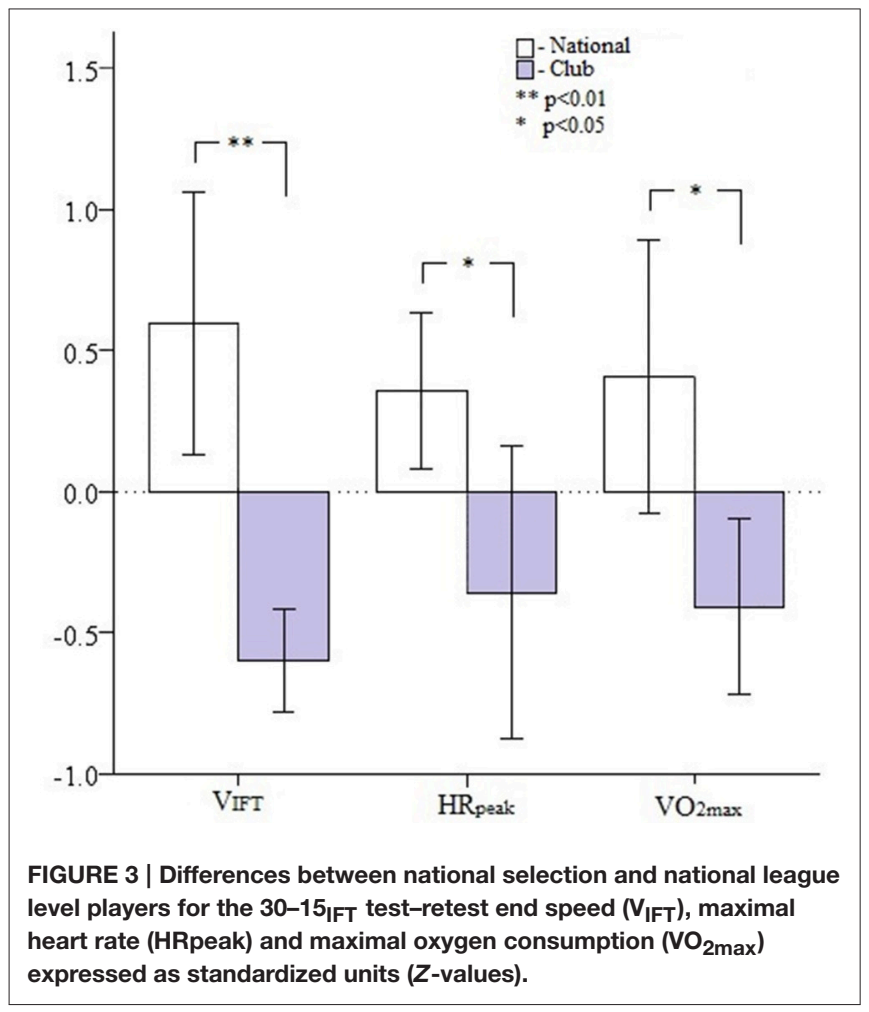

high-intensity running intervals during matches in comparison to their sub-elite counterparts. Since, the stage (speed) at which exhaustion occurs during incremental aerobic tests and the number of high intensity running intervals performed are highly related ( $r=0.82$ ) (Rampinini et al., 2007); it can be argued that 30-15 IFT performance may be used to differentiate between elite and sub-elite intermittent sport athletes. Future research assessing the relationships between $30-15_{\text {IFT }}$ performance and match kinematics (e.g., running intensity, distance covered, HR variation) in elite female intermittent team sport athletes may provide coaches with individual and positional specific diagnostics to better inform training and possibly match strategy.

In summary, the $30-15_{\text {IFT }}$ is reliable, valid and practically useful to assess and monitor maximal aerobic fitness (HRpeak and $\mathrm{V}_{\text {IFT }}$ ) changes in female soccer players. The current findings have provided evidence and guidelines for the meaningful detection of the intermittent fitness test performance changes. The authors suggest that further research in female soccer players focus on examining (i) the differences in 30-15 IFT performance based on playing position, (ii) individual differences as they relate to anthropometric and morphological characteristics, especially body mass index (Nikolaidis, 2014a) and (iii) individual and group 30-15 IFT performance adaptations to acute and chronic anaerobic and aerobic training.

\section{CONCLUSION}

As previously iterated, the $30-15_{\text {IFT }}$ is a practical, valid, useful, inexpensive, and efficient aerobic intermittent field test. The test can be administered to large groups (20-30 athletes) outdoors or indoors in a relatively short amount of time ( $\sim 20$ min per test). Furthermore, the exhaustive sensation is lower compared to similar field tests making it useful during the preparatory (off-season and pre-season) and competitive training phases. Scientists and coaches should monitor changes in $V_{\text {IFT }}$ to determine "meaningful" intermittent aerobic fitness changes in response to training and/or detraining. The following "meaningful" individual changes in 30-15 IFT performance have been proposed: $0.5 \mathrm{~km} / \mathrm{h}$ ( $\mathrm{V}_{\text {IFT }}$ ) and 2 b.p.m (HRpeak). A group performance change of $6-8 \%$ in $\mathrm{V}_{\text {IFT }}$ is required to be deemed as "real." The $30-15_{\text {IFT }}$, may be more advantageous than other intermittent aerobic fitness tests in monitoring physical performance changes for intermittent sports, as is the test provides $\mathrm{V}_{\mathrm{IFT}}$, HRpeak, an indirect estimate of $\mathrm{VO}_{2 \max }$ during high intensity running efforts (Thomas et al., 2015). It must be emphasized that the test is designed to accurately assess small intermittent running intensity differences $\left(\mathrm{V}_{\mathrm{IFT}}\right.$ changes of $0.5 \mathrm{~km} / \mathrm{h}$ ) and provide individualized aerobic training velocities and distances (Buchheit, 2008). It must be noted that HRpeak herein, as determined via direct and indirect aerobic fitness tests is a stable measure, and should not be confused with resting and/or submaximal heart rate variability, where day-to-day fluctuations of $10 \mathrm{SD}$ units are commonly observed (Umetani et al., 1998). Due to the nature of 30-

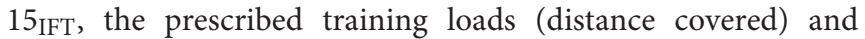
cardiorespiratory demands experienced by each athlete will be similar across a squad regardless of individual $\mathrm{V}_{\mathrm{IFT}}$. It is also suggested that testing conditions (e.g., temperature, humidity, altitude, surface, footwear, and testing time) be controlled and standardized across testing sessions to allow for accurate performance monitoring. 


\section{AUTHOR CONTRIBUTIONS}

NČ, EJ: Substantial contributions to the conception or design of the work; HA, EK: The acquisition, analysis, or

\section{REFERENCES}

Andersson, H. Å., Randers, M. B., Heiner-Møller, A., Krustrup, P., and Mohr, M. (2010). Elite female soccer players perform more high-intensity running when playing in international games compared with domestic league games. J. Strength Cond. Res. 24, 912-919. doi: 10.1519/JSC.0b013e3181d09f21

Bangsbo, J., Iaia, F. M., and Krustrup, P. (2008). The Yo-Yo intermittent recovery test. Sports Med. 38, 37-51. doi: 10.2165/00007256-200838010-00004

Bradley, P. S., Bendiksen, M., Dellal, A., Mohr, M., Wilkie, A., Datson, N., et al. (2014). The application of the Yo-Yo intermittent endurance level 2 test to elite female soccer populations. Scand. J. Med. Sci. Sports 24, 43-54. doi: $10.1111 / \mathrm{j} .1600-0838.2012 .01483 . x$

Buchheit, M. (2005). 30-15 Intermittent Fitness Test. Strasbourg: Martin Buchheit.

Buchheit, M. (2008). The 30-15 intermittent fitness test: accuracy for individualizing interval training of young intermittent sport players. J. Strength Cond. Res. 22, 365-374. doi: 10.1519/JSC.0b013e3181635b2e

Buchheit, M. (2010). The 30-15 intermittent fitness test: 10 year review. Myorobie J. 1, 278.

Buchheit, M., Al Haddad, H., Millet, G. P., Lepretre, P. M., Newton, M., and Ahmaidi, S. (2009a). Cardiorespiratory and cardiac autonomic responses to 30-15 intermittent fitness test in team sport players. J. Strength Cond. Res. 23, 93-100. doi: 10.1519/JSC.0b013e31818b9721

Buchheit, M., Laursen, P. B., Al Haddad, H., and Ahmaidi, S. (2009b). Exercise-induced plasma volume expansion and post-exercise parasympathetic reactivation. Eur. J. Appl. Physiol. 105, 471-481. doi: 10.1007/s00421-0080925-1

Buchheit, M., Laursen, P. B., Kuhnle, J., Ruch, D., Renaud, C., and Ahmaidi, S. (2009c). Game-based training in young elite handball players. Int. J. Sports Med. 30, 251. doi: 10.1055/s-0028-1105943

Buchheit, M., Lefebvre, B., Laursen, P. B., and Ahmaidi, S. (2011). Reliability, usefulness, and validity of the 30-15 intermittent ice test in young elite ice hockey players. J. Strength Cond. Res. 25, 1457-1464. doi: 10.1519/JSC.0b013e3181d686b7

Buchheit, M., and Rabbani, A. (2014). The 30-15 intermittent fitness test versus the yo-yo intermittent recovery test level 1: relationship and sensitivity to training. Int. J. Sports Physiol. Perform. 9, 522-524. doi: 10.1123/ijspp.2012-0335

Castagna, C., Impellizzeri, F. M., Chamari, K., Carlomagno, D., and Rampinini, E. (2006). Aerobic fitness and yo-yo continuous and intermittent tests performances in soccer players: acorrelation study. J. Strength Cond. Res. 20, 320-325. doi: 10.1519/00124278-200605000-00015

Duffield, R., Dawson, B., Pinnington, H., and Wong, P. (2004). Accuracy and reliability of a Cosmed K4b 2 portable gas analysis system. J. Sci. Med. Sport 7, 11-22. doi: 10.1016/S1440-2440(04)80039-2

Dupont, G., Defontaine, M., Bosquet, L., Blondel, N., Moalla, W., and Berthoin, S. (2010). Yo-Yo intermittent recovery test versus the universite de montreal track test: relation with a high-intensity intermittent exercise. J. Sci. Med. Sport 13, 146-150. doi: 10.1016/j.jsams.2008.10.007

Haydar, B., Al Haddad, H., Ahmaidi, S., and Buchheit, M. (2011). Assessing intereffort recovery and change of direction ability with the 30-15 Intermittent Fitness Test. J. Sports Sci. Med. 10, 346-354.

Hopkins, W. (2007). Reliability from Consecutive Pairs of Trials (Excel Spreadsheet). A new view of statistics. sportsci. org: Internet Society for Sport Science.

Hopkins, W. G. (2004). How to interpret changes in an athletic performance test. Sportscience 8, 1-7.

Hopkins, W. G., Schabort, E. J., and Hawley, J. A. (2001). Reliability of power in physical performance tests. Sports Med. 31, 211-234. doi: 10.2165/00007256200131030-00005

Krustrup, P., and Bangsbo, J. (2001). Physiological demands of top-class soccer refereeing in relation to physical capacity: effect of intense intermittent exercise training. J. Sports Sci. 19, 881-891. doi: 10.1080/026404101753113831

Krustrup, P., Mohr, M., Ellingsgaard, H., and Bangsbo, J. (2005). Physical demands during an elite female soccer game: importance of training status. Med. Sci. Sports Exerc. 37, 1242. doi: 10.1249/01.mss.0000170062.73981.94 interpretation of data for the work; ZM, GS, DM: Drafting the work or revising it critically for important intellectual content; IR, DM: Final approval of the version to be published.

Léger, L., Mercier, D., Gadoury, C., and Lambert, J. (1988). The multistage 20 metre shuttle run test for aerobic fitness. J. Sports Sci. 6, 93-101.

MK Tood, D. S., and Chisnal, P. (2013). "62 Fitness characteristics of english female soccer players: an analysis by position and playing standard," in Science and Football IV, eds W. Spinks, T. Reilly, and A. Murphy (New York, NY: Routledge), 374.

Mohr, M., Krustrup, P., Andersson, H., Kirkendal, D., and Bangsbo, J. (2008). Match activities of elite women soccer players at different performance levels. J. Strength Cond. Res. 22, 341-349. doi: 10.1519/JSC.0b013e318165fef6

Nikolaidis, P. (2010). Physiological characteristics of elite Greek female soccer players. Med. Dello Sport 63, 343-351.

Nikolaidis, P. T. (2014a). Weight status and physical fitness in female soccer players: is there an optimal BMI? Sport Sci. Health 10, 41-48. doi: 10.1007/s11332-014-0172-2

Nikolaidis, P. T. (2014b). Physical fitness in female soccer players by player position: a focus on anaerobic power. Hum. Mov. 15, 74-79. doi: 10.2478/humo-2014-0006

Pierce, C. A., Block, R. A., and Aguinis, H. (2004). Cautionary note on reporting eta-squared values from multifactor ANOVA designs. Educ. Psychol. Meas. 64, 916-924. doi: 10.1177/0013164404264848

Rabbania, A., and Buchheita, M. (2015). "13 Heart rate-based versus speedbased high-intensity interval training in young soccer players," in International Research in Science and Soccer II, eds T. Favero, B. Drust, and B. Dawson (New York, NY: Routledge), 119.

Rampinini, E., Bishop, D., Marcora, S., Ferrari Bravo, D., Sassi, R., and Impellizzeri, F. (2007). Validity of simple field tests as indicators of match-related physical performance in top-level professional soccer players. Int. J. Sports Med. 28, 228-235. doi: 10.1055/s-2006-924340

Rhodes, E., and Mosher, R. (1992). Aerobic and anaerobic characteristics of elite female university players. J. Sports Sci. 10, 143-144.

Scott, T. J., Delaney, J. A., Duthie, G. M., Sanctuary, C. E., Ballard, D. A., Hickmans, J. A., et al. (2015). Reliability and usefulness of the 30-15 intermittent fitness test in rugby league. J. Strength Cond. Res. 29, 1985-1990. doi: 10.1519/JSC.0000000000000846

Taylor, H. L., Buskirk, E., and Henschel, A. (1955). Maximal oxygen intake as an objective measure of cardio-respiratory performance. J. Appl. Physiol. 8, 73-80.

Thomas, A., Dawson, B., and Goodman, C. (2006). The Yo-Yo Test: reliability and association with a $20-\mathrm{m}$ shuttle run and VO 2 max. Int. J. Sports Physiol. Perform. 1, 137-149. doi: 10.1123/ijspp.1.2.137

Thomas, C., Dos' Santos, T., Jones, P., and Comfort, P. (2015). Reliability of the 30-15 intermittent fitness test in semi-professional soccer players. Int. J. Sports Physiol. Perform. 1, 137-149. doi: 10.1123/ijspp.2015-0056

Uger, L., and Boucher, R. (1980). An indirect continuous running multistage field test: the Universite de Montreal track test. Can. J. Appl. Sport. Sci. 5, 77-84.

Umetani, K., Singer, D. H., McCraty, R., and Atkinson, M. (1998). Twenty-four hour time domain heart rate variability and heart rate: relations to age and gender over nine decades. J. Am. Coll. Cardiol. 31, 593-601. doi: 10.1016/S07351097(97)00554-8

Weissland, T., Faupin, A., Borel, B., and Leprêtre, P.-M. (2015). Comparison between 30-15 intermittent fitness test and multistage field test on physiological responses in wheelchair basketball players. Front. Physiol. 6:380. doi: $10.3389 /$ fphys.2015.00380

Conflict of Interest Statement: The authors declare that the research was conducted in the absence of any commercial or financial relationships that could be construed as a potential conflict of interest.

Copyright (c) 2016 Čović, Jelešković, Alić, Rađo, Kafedžić, Sporiš, McMaster and Milanovic. This is an open-access article distributed under the terms of the Creative Commons Attribution License (CC BY). The use, distribution or reproduction in other forums is permitted, provided the original author(s) or licensor are credited and that the original publication in this journal is cited, in accordance with accepted academic practice. No use, distribution or reproduction is permitted which does not comply with these terms. 